\section{Cureus}

\title{
Ultra-high-frequency Ultrasound to Assess Nerve Fascicles in Median Nerve Traumatic Neuroma
}

Antonio J. Forte ${ }^{1}$, Daniel Boczar ${ }^{2}$, Jeremie D. Oliver ${ }^{3}$, Andrea Sisti ${ }^{2}$, Steven R. Clendenen ${ }^{4}$

1. Plastic Surgery, Robert D. and Patricia E. Kern Center for the Science of Health Care Delivery, Mayo Clinic, Jacksonville, USA 2. Plastic Surgery, Mayo Clinic, Jacksonville, USA 3. Plastic Surgery, Mayo Clinic, Rochester, USA 4. Anesthesiology, Mayo Clinic, Jacksonville, USA

$\square$ Corresponding author: Steven R. Clendenen, clendenen.steven@mayo.edu Disclosures can be found in Additional Information at the end of the article

\section{Abstract}

A traumatic neuroma is a major cause of persistent neuropathic pain. Diagnostic imaging tools are critical to the success of surgical treatment. Ultra-high-frequency ultrasound is a novel technology that can generate frequencies up to $70 \mathrm{MHz}$, assessing structures up to $30 \mu \mathrm{m}$. We report a unique case of intraoperative use of ultra-high-frequency ultrasound to provide detailed imaging of nerve fascicles, facilitating surgical excision of the mass.

Categories: Plastic Surgery, Radiology, Orthopedics

Keywords: ultra-high-frequency ultrasound, neuroma, nerve fascicles

\section{Introduction}

According to the National Institutes of Health, chronic pain is the leading cause of long-term disability in the United States. Traumatic neuroma stands as one of the most relevant causes of persistent neuropathic pain [1]. It is a consequence of a nerve-mending process which could affect any part of the body after external trauma or surgery. It is not classified as a neoplastic process but a disorganized proliferation of nerve axons, Schwann cells, and perineural fibroblasts following Wallerian nerve degeneration [2]. Ultra-high-frequency ultrasound (UHFUS) is a new technology in clinical diagnostic imaging. It can generate frequencies up to $70 \mathrm{MHz}$, assessing structures up to $30 \mu \mathrm{m}$. It is feasible to capture previously indistinguishable anatomic details, such as nerve fascicles [3]. UHFUS will soon become a widespread tool available at most hospitals, and its superior imaging of delicate structures should be tested on challenging lesions, such as traumatic neuromas.

Received 05/09/2019 Review began 05/24/2019 Review ended 06/05/2019 Published 06/10/2019

\section{(C) Copyright 2019}

Forte et al. This is an open access article distributed under the terms of the Creative Commons Attribution License CC-BY 3.0., which permits unrestricted use, distribution, and reproduction in any medium, provided the original author and source are credited.

\section{Case Presentation}

A 71-year-old man presented with a history of right wrist pain for several years with increasing intensity over the past year and a half. Radiography showed advanced osteoarthritic changes. The patient also reported occasional paresthesias on the median nerve dermatome distribution. He stated that he had a wrist laceration 20 years prior with what he believed was a median nerve partial transection, leaving him with numbness in the thumb, index, and middle fingers that improved over time after the initial surgical nerve repair. As part of the pain and paresthesia evaluation, magnetic resonance imaging (MRI) was ordered. This study described a mass enlargement of the median nerve consistent with a peripheral nerve sheath tumor, such as a fibroma or schwannoma, with a heterogeneous increased $\mathrm{T} 2$ signal of the median nerve proximal to the carpal tunnel measuring approximately $16 \mathrm{~mm}$ x $10 \mathrm{~mm}$ x $6 \mathrm{~mm}$ (Figure 1). 


\section{Cureus}
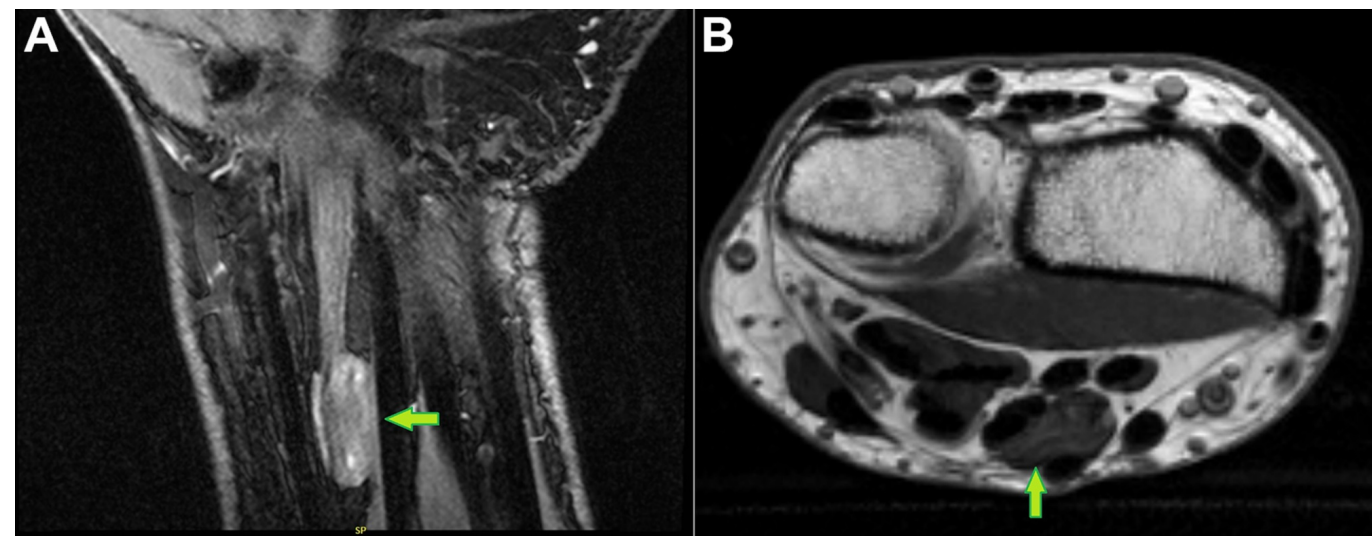

FIGURE 1: Magnetic Resonance Imaging of the Wrist

Green arrows point to the median nerve mass: A) coronal view; B) axial view

The nerve appeared normal proximal and distal to this level. The patient agreed to surgical exploration with UHFUS examination which helped delineate where the mass was in relation to the nerve fascicles (Figure 2).

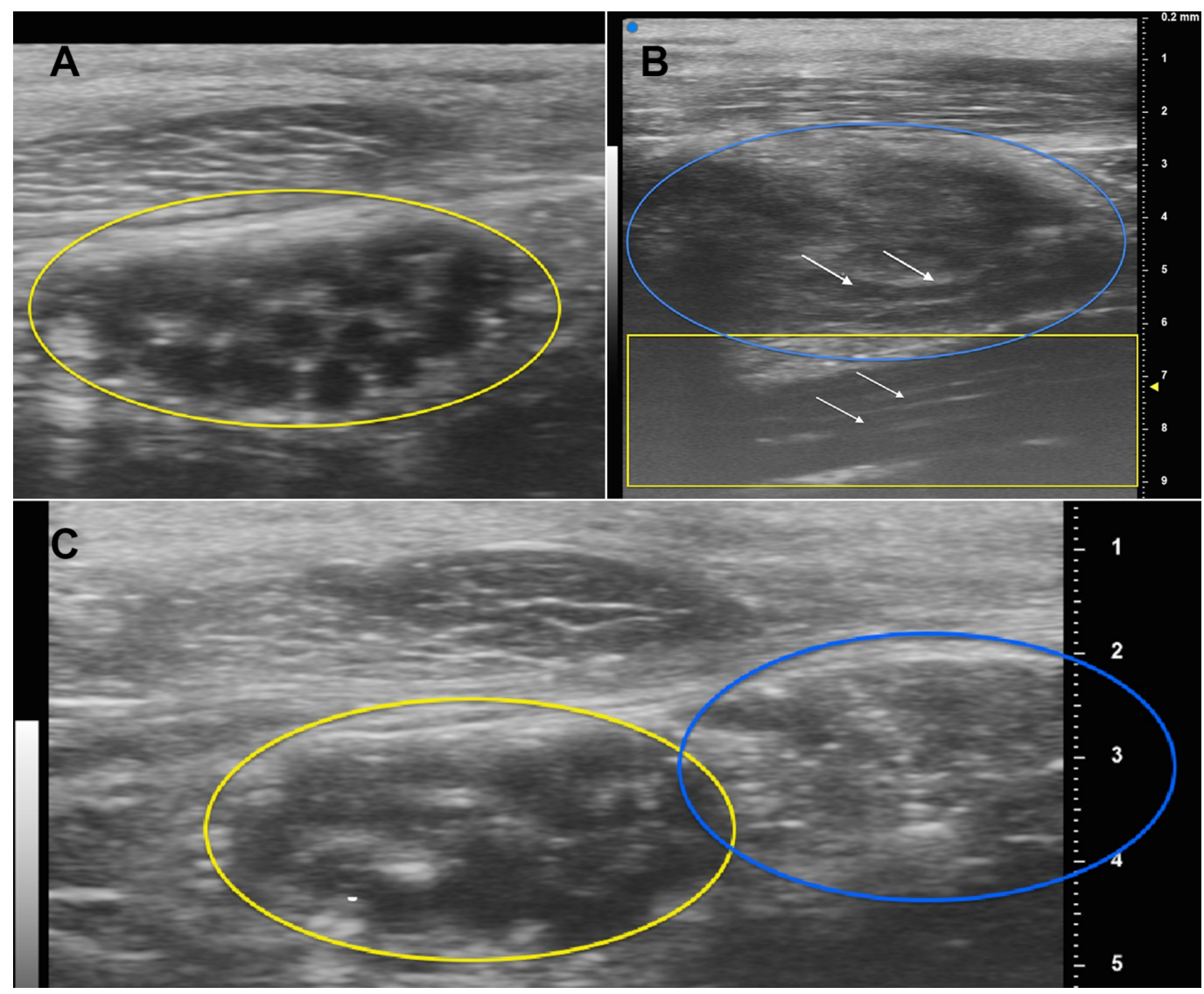

FIGURE 2: Ultra-high-frequency Ultrasound Images

A) Cross-section of the median nerve distal to the neuroma (yellow oval); B) long axis of the neuroma (blue oval) and median nerve (yellow box); white arrows point to the long axis of the median nerve fascicles; C) cross-section of the median nerve (yellow oval) and neuroma (blue oval). 


\section{Cureus}

Under microscope magnification, an interfascicular dissection was performed and the mass was excised (Figure 3).
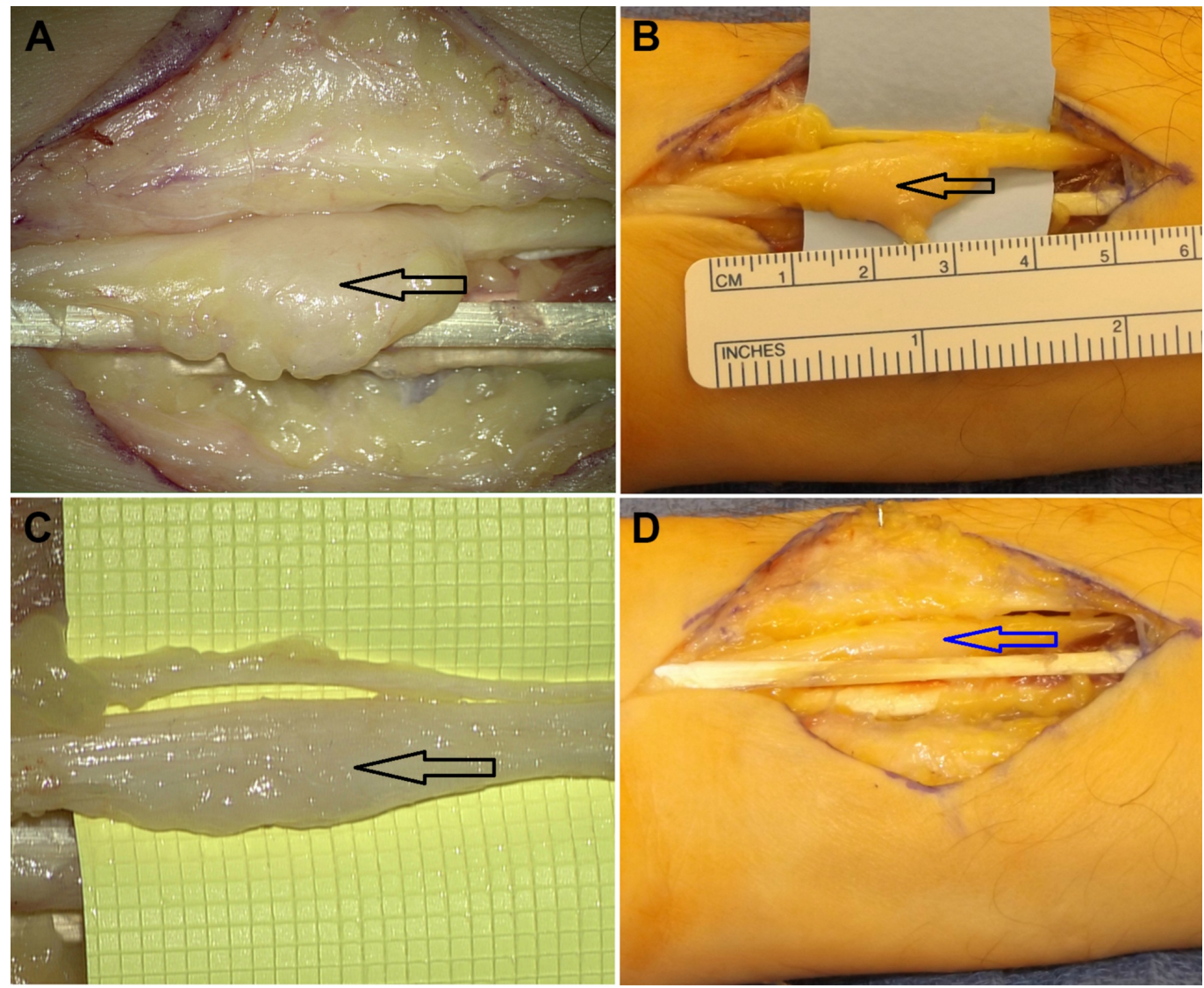

\section{FIGURE 3: Intraoperative Image}

A-B) Before resection of the neuroma (black arrows); C) intraoperative microscopic view of the neuroma, X8 magnification (black arrow); D) macroscopic view after resection of the neuroma (blue arrow).

Pathologic examination identified the mass as a traumatic neuroma.

\section{Discussion}

UHFUS is a novel technology with few clinical applications described in the literature. Its capacity to visualize small structures can assess nerve fascicles, allowing surgical removal of neuromas with nerve function preservation. To our knowledge, this is the first report of the application of UHFUS in the evaluation of traumatic neuroma. Traumatic neuromas have anomalous anatomy, the consequence of adhesions, scar tissue, and foreign bodies [1]. Diagnostic imaging tools, such as MRI and ultrasound, are considered fundamental for the success of the operation, preventing postsurgical neurologic deficits [4-5]. Ulatowski and Kaniewska [6] provided some evidence that peripheral neural sheath tumors could be removed with nerve preservation. However, they suggested that these surgeries should be performed in microsurgery centers for careful intraoperative evaluation. MRI has been proven to be the most effective imaging modality for visualization of neuromas, but ultrasonography is frequently used due to lower cost and feasibility of dynamic images, allowing nerve continuity visualization [7-8]. Aggarwal et al. [9] pointed out that conventional ultrasound fails to 
determine nerve continuity in cases where fibrosis and architectural distortion are found, as in traumatic neuromas. Lee and Yoon [4] evaluated the ultrasonographic findings of a schwannoma of the hand and reported that diagnosis was challenging when using ultrasound alone because small lesions may mimic nerve ganglion, leading to a misdiagnosis. In our case, UHFUS examination assisted us in identifying this lesion as a neuroma instead of a schwannoma, as suggested by the MRI, allowing us to optimize fascicle identification and safely proceed with surgery. However, these higher ultrasonic frequencies have lower pulse lengths, which reduce tissue penetration and limit its utility to superficial anatomical structures.

\section{Conclusions}

We report the use of UHFUS for detailed visualization of nerve fascicles previously inaccessible with other imaging modalities. A better awareness of the anatomy can guide surgeon decisions about nerve preservation, thus optimizing the procedure. We strongly encourage further studies addressing the use of UHFUS for neuromas and nerve tumors.

\section{Additional Information \\ Disclosures}

Human subjects: Consent was obtained by all participants in this study. Conflicts of interest: In compliance with the ICMJE uniform disclosure form, all authors declare the following: Payment/services info: All authors have declared that no financial support was received from any organization for the submitted work. Financial relationships: All authors have declared that they have no financial relationships at present or within the previous three years with any organizations that might have an interest in the submitted work. Other relationships: All authors have declared that there are no other relationships or activities that could appear to have influenced the submitted work.

\section{References}

1. Symeonidis P, Daniilidis N, Givissis P: A simple method of skin mapping for planning the operative approach in peripheral nerve injuries. Acta Neurochir (Wien). 2015, 157:1953-58. 10.1007/s00701-015-2561-y

2. Aslan A, Konya MN, Sargin S: Post-traumatic median nerve neuroma in wrist. A case report and brief review of literature. J Orthop Case Rep. 2013, 3:38-41. 10.13107/jocr.2250-0685.114

3. Kowalska B: Assessment of the utility of ultrasonography with high-frequency transducers in the diagnosis of posttraumatic neuropathies. J Ultrason. 2015, 15:15-28.

10.15557/JoU.2015.0002

4. Lee SJ, Yoon ST: Ultrasonographic and clinical characteristics of schwannoma of the hand . Clin Orthop Surg. 2017, 9:91-95. 10.4055/cios.2017.9.1.91

5. Chiou HJ, Chou YH, Chiou SY, Liu JB, Chang CY: Peripheral nerve lesions: role of highresolution US. Radiographics. 2003, 23:e15. 10.1148/rg.e15

6. Ulatowski Ł, Kaniewska A: Neurilemoma of the median nerve - surgical strategies based on a case report. Pol Przegl Chir. 2014, 86:429-32. 10.2478/pjs-2014-0076

7. Chen KH, Lee KF, Hsu HC, Huang WC, Hsiao KY, Fang KM: The role of high-resolution ultrasound in the diagnosis of a traumatic neuroma in an injured median nerve. Am J Phys Med Rehabil. 2009, 88:771-74. 10.1097/PHM.0b013e3181b332ef

8. Alaqeel A, Alshomer F: High resolution ultrasound in the evaluation and management of traumatic peripheral nerve injuries: review of the literature. Oman Med J. 2014, 29:314-19. 10.5001/omj.2014.86

9. Aggarwal A, Srivastava DN, Jana M, et al.: Comparison of different sequences of magnetic resonance imaging and ultrasonography with nerve conduction studies in peripheral neuropathies. World Neurosurg. 2017, 108:185-200. 10.1016/j.wneu.2017.08.054 